\title{
Molecular weight of barley $\beta$-glucan influences energy expenditure, gastric emptying and glycaemic response in human subjects
}

\author{
P. S. Thondre ${ }^{1}$, A. Shafat ${ }^{2}$ and M. E. Clegg ${ }^{1 *}$ \\ ${ }^{1}$ Department of Sport and Health Sciences, Faculty of Health and Life Sciences, Functional Food Centre, \\ Oxford Brookes University, Gipsy Lane, Oxford OX3 OBP, UK \\ ${ }^{2}$ Department of Physiology, School of Medicine, National University of Ireland, Galway, Republic of Ireland \\ (Submitted 18 January 2013 - Final revision received 23 April 2013 - Accepted 29 April 2013 - First published online 7 June 2013)
}

\begin{abstract}
Barley $\beta$-glucan (BG) has been shown to reduce glycaemic response (GR) in some studies. It is hypothesised that this reduction may be a function of its physical properties that delay gastric emptying (GE). The effect of these changes in GR and GE on diet-induced thermogenesis (DIT) is not known. The aim of the present study was to assess the effect of BG of different molecular weights and purities on GR, GE and DIT in healthy subjects. This was a randomised, single-blind, repeated-measures design where fifteen healthy subjects were tested on three occasions following an overnight fast. Following the baseline measurements, the volunteers were fed a soup containing high-molecular-weight BG (HBG), a soup containing low-molecular-weight BG (LBG) or a control soup with no BG (CHO). Following the consumption of the breakfast, GR was measured using finger-prick blood samples, GE was determined using the ${ }^{13} \mathrm{C}$-octanoic acid breath test and DIT was measured using indirect calorimetry. There was a difference in GR AUC between the soups after 60 min but not after $120 \mathrm{~min}$. The CHO and LBG meals had a greater GR than the HBG meal. There were differences in all GE time points, with the HBG meal having the slowest GE time. There was a correlation between the GR and the initial GE times. There were differences in total DIT between the three test meals with the HBG meal having the lowest DIT. The present study indicates that HBG has the ability to delay GE due to increased viscosity, resulting in a decreased GR and DIT.
\end{abstract}

Key words: Barley $\beta$-glucan: Glycaemic responses: Diet-induced thermogenesis: Gastric emptying

A worldwide increase in type 2 diabetes along with the prevalence of obesity has prompted the development of nutritional and lifestyle interventions to improve glycaemia and increase energy expenditure. Soluble dietary fibres may have beneficial effects on glycaemic and insulin responses and cholesterol levels as well as body weight maintenance ${ }^{(1-3)}$. Barley $\beta$-glucan (BG) is one such fibre that forms a highly viscous solution in the stomach and small intestine, which entraps glucose molecules and slows down their intestinal absorption $^{(4)}$. However, barley BG in foods has not always been effective in lowering glycaemic response $(G R)^{(5-8)}$ due to variations in its physical properties such as molecular weight and viscosity. Soluble fibres in foods may increase gastric distension, delay gastric emptying (GE) and alter the levels of gut hormones involved in appetite and satiety ${ }^{(9,10)}$. However, the effect of BG on GE has shown variation with meal consistency and is not always correlated with $\mathrm{GR}^{(11)}$. On the other hand, delayed GE has been reported irrespective of any difference in GR or satiety ${ }^{(12)}$. Juvonen et al. ${ }^{(13)}$ reported changes in glycaemia, insulinaemia and GE after reducing the viscosity of oat $\mathrm{BG}$ in a liquid meal. Elsewhere, the reduced GR could not be associated with a delayed GE rate $^{(14)}$. Hence, it is evident that the variable effect of BG on GE is not fully understood.

Low-glycaemic index foods have been shown to increase satiety and decrease hunger ${ }^{(15,16)}$, yet there is no evidence of low-glycaemic index foods resulting in weight $\operatorname{loss}^{(17,18)}$ due to problems in study designs, lack of sufficient data on energy expenditure and substrate oxidation. Diet-induced thermogenesis (DIT) is the amount of energy required for the absorption and metabolism of food and represents $10 \%$ of the total energy expenditure ${ }^{(19)}$. Some studies ${ }^{(20-22)}$ have shown the ability of low-glycaemic index foods to increase DIT, and the ingestion of soluble dietary fibres is one such method that may be explored further ${ }^{(23)}$.

The role of cereal BG in DIT has not been studied or understood yet. Therefore, we hypothesised that barley BG will increase DIT and the effect will depend on its molecular

Abbreviations: BG, $\beta$-glucan; CHO, control soup with no $\beta$-glucan; DIT, diet-induced thermogenesis; GE, gastric emptying; GR, glycaemic response; HBG, high-molecular-weight $\beta$-glucan; iAUC, incremental AUC; LBG, low-molecular-weight $\beta$-glucan; $T_{\text {half, half-time. }}$ 
weight and viscosity. Hence, the main objective of the present study was to investigate the effect of barley BG in a semi-solid meal on postprandial GR, GE, short-term satiety and DIT in healthy subjects. A secondary objective was to examine the differences in the above-mentioned responses depending on the variation in purity and molecular weight of the BG used.

\section{Methods}

The present study was a randomised, single-blind, repeatedmeasures design with volunteers being fed three different test meals on three different days.

\section{Subjects}

Fifteen healthy subjects (three males and twelve females, age 27.6 (sD 5.9) years, height 168.7 (sD 7.4) cm, weight $67 \cdot 4$ (SD 13.3) $\mathrm{kg}$ and BMI $23.5(\mathrm{sD} 3.0) \mathrm{kg} / \mathrm{m}^{2}$ ) were recruited for the study by means of advertisements and personal communications over a period of 3 months. Before inclusion into the study, potential participants were briefed on all aspects of the experiment and were given the opportunity to ask questions. This was followed by a health assessment, which included anthropometric measurements and a health questionnaire (giving details of food allergies/intolerances, metabolic diseases, special dietary needs and smoking habits). Those who fulfilled all the acceptable criteria (age 18-60 years, BMI $<30 \mathrm{~kg} / \mathrm{m}^{2}$, blood pressure $110-120 / 75-85$ $\mathrm{mmHg}$, fasting blood glucose levels $<6 \mathrm{mmol} / 1$, not on prescription medication, and no genetic or metabolic diseases) were included in the study. On the day before each test, the subjects were asked to restrict their intake of alcohol and caffeine-containing drinks and to refrain from any strenuous physical activity.

The present study was conducted according to the guidelines laid down in the Declaration of Helsinki, and all procedures involving human subjects were approved by the Oxford Brookes University Research Ethics Committee. Written informed consent was obtained from all subjects/ patients. On each test day, the subjects arrived between 07.00 and 09.00 hours in the morning after an overnight fasting (10-12 $\mathrm{h}$ before testing time) and without undertaking any physical activity.

\section{Test meals}

The test meals consisted of a soup (Potato and Leek, Cup a Soup, Batchelors; Premier Foods Group). The energy and macronutrient composition of the test meals are given in Table 1. Available carbohydrates were calculated for each test meal using the Food and Agricultural Organization/ WHO procedure ${ }^{(24)}$ according to the nutrition information available from the soup label and the BG suppliers (Polycell Technologies) to provide $25 \mathrm{~g}$ of available carbohydrates. Barley balance with a purity of $25 \%$ was used as the source of high-molecular-weight BG (HBG). Glucagel with a purity of $75 \%$ was used as the source of low-molecular-weight BG (LBG). Both were provided by DKSH Great Britain Limited.
Table 1. Energy and nutrient composition of the soup test meals - high-molecular-weight $\beta$-glucan (HBG), lowmolecular-weight $\beta$-glucan (LBG) or a control containing no $\beta$-glucan $(\mathrm{CHO})^{*}$

\begin{tabular}{|c|c|c|c|}
\hline & HBG & LBG & $\mathrm{CHO}$ \\
\hline Meal size (g) & $48 \cdot 70$ & $46 \cdot 66$ & 43.43 \\
\hline \multicolumn{4}{|l|}{ Energy } \\
\hline $\mathrm{kJ}$ & $797 \cdot 75$ & 809.93 & 783.51 \\
\hline kcal & 189.94 & $192 \cdot 84$ & 186.55 \\
\hline Total carbohydrate (g) & 31.94 & $31 \cdot 22$ & $28 \cdot 25$ \\
\hline Available carbohydrate (g) & 25 & 25 & 25 \\
\hline Total fibre $(g)$ & $6 \cdot 94$ & $6 \cdot 22$ & $3 \cdot 25$ \\
\hline Protein $(\mathrm{g})$ & $5 \cdot 14$ & $3 \cdot 71$ & 3.57 \\
\hline Lipid (g) & $6 \cdot 17$ & $7 \cdot 28$ & $7 \cdot 31$ \\
\hline \multicolumn{4}{|l|}{$\beta$-Glucan } \\
\hline$g$ & $12 \cdot 88$ & $3 \cdot 61$ & - \\
\hline$\%$ of purity & 25 & 75 & - \\
\hline Carbohydrate (\%) & $67 \cdot 27$ & $64 \cdot 77$ & $60 \cdot 57$ \\
\hline Protein (\%) & $10 \cdot 82$ & $7 \cdot 70$ & $7 \cdot 66$ \\
\hline Lipid (\%) & $29 \cdot 22$ & $27 \cdot 79$ & $28 \cdot 98$ \\
\hline
\end{tabular}

The preparation of the meals was according to the product instructions. The subjects were blinded as to which soup they consumed on each test day.

\section{Study design}

The volunteers participated in a randomised, balanced, controlled cross-over study where they consumed a high-BG (HBG) soup, a low-BG (LBG) soup and a control (CHO) soup with no BG on separate days in a random order. The volunteers were randomly assigned each day's test meal using a pseudo-random number generator by setting a random seed (using srand, a function in the programming language $\mathrm{C}$ ) and by shuffling the order with no restrictions. This was completed by one researcher and testing itself was undertaken by another researcher. On the day before testing, the volunteers were asked to record the food they consumed and repeat it before subsequent tests.

\section{Energy expenditure}

On arrival to the laboratory, the volunteers were asked to rest for $30 \mathrm{~min}$ in a supine position on a bed before baseline measurements of RMR were taken. RMR was determined in the morning between 07.00 and 09.00 hours. RMR was measured at $1 \mathrm{~min}$ intervals for $30 \mathrm{~min}$ under the ventilated hood indirect calorimetry system (Deltatrac ${ }^{\mathrm{TM}}$ II Metabolic Monitor; Datex-Ohmeda, Inc.). The analyser was calibrated on each test day with standardised gases containing $5 \% \mathrm{CO}_{2}$ and $95 \% \mathrm{O}_{2}$.

DIT was determined for $180 \mathrm{~min}$ after the ingestion of the test meal, with measurements taken for $15 \mathrm{~min}$ in every $30 \mathrm{~min}^{(25)}$. The first $5 \mathrm{~min}$ of every $15 \mathrm{~min}$ time period were discarded to allow for stabilisation within the Deltatrac hood, and the average of the remaining $10 \mathrm{~min}$ was used. This time period was recommended to be appropriate to measure the thermic effect of foods ${ }^{(25)}$. DIT was calculated as the increase in energy 
expenditure per min above pre-meal values for $3 \mathrm{~h}$ after the intake of a meal. Energy expenditure and fat oxidation were calculated using the equations of Lusk ${ }^{(26)}$.

\section{Glycaemic response}

The protocol used to measure the blood glucose response was adopted from that described by Brouns et al. ${ }^{(27)}$, and it is in line with the procedures recommended by the Food and Agricultural Organization/ $/ \mathrm{WHO}^{(24)}$. Blood was obtained by finger prick using the Unistik 3 single-use lancing device (Owen Mumford). Before a finger prick, the subjects were encouraged to warm their hand to increase blood flow. To minimise plasma dilution, fingertips were not squeezed to extract blood but instead gently massaged starting from the base of the hand moving towards the tips. The first two drops of the extracted blood were discarded, and the next drop was used for testing.

Blood glucose levels were measured using the HemoCue $201+$ Glucose analyser (HemoCue Limited). The HemoCue method is reliable for blood glucose analysis ${ }^{(28)}$. Fasting blood samples were taken at -5 and $0 \mathrm{~min}$, and the test food was consumed immediately afterwards within $15 \mathrm{~min}$ at a comfortable pace. Further blood samples were then taken at 15, 30, 45, 60, 90, 120, 150 and $180 \mathrm{~min}$ after the consumption of the test meal.

The change in GR was calculated by computing the difference between the blood glucose concentration at a time point and the mean baseline blood glucose concentration (based on two baseline values recorded 5 min apart). Because it represented the relative increment in the GR at any time point compared with the baseline value, it was this change in GR that was used for all further analyses, including incremental AUC (iAUC) calculations, blood glucose response curve construction and statistics. The total blood glucose response was expressed as the iAUC ignoring the area beneath the baseline and was calculated geometrically using the trapezoidal rule ${ }^{(26,29)}$.

\section{Gastric emptying}

In the present study, $100 \mathrm{mg}$ of $\left[1-{ }^{13} \mathrm{C}\right]$ sodium acetate were used to measure GE as acetate is hydrophilic, poorly absorbed in the stomach and rapidly metabolised after absorption. Sodium $\left[1-{ }^{13} \mathrm{C}\right]$ acetate is considered a reliable and valid substance for identifying changes in GE of semi-solids ${ }^{(30)}$. Breath samples were collected by making the volunteers blow gently into a $10 \mathrm{ml}$ Exetainer (Labco) with a drinking straw and replacing the cap just before the end of exhalation. Breath samples were analysed using isotope ratio MS (ABCA), and the results were expressed relative to ViennaPDB, an international standard for known ${ }^{13} \mathrm{C}$ composition. ${ }^{13} \mathrm{CO}_{2}$ values were expressed as the excess amount in the breath above the baseline and converted into moles. $\mathrm{CO}_{2}$ production was assumed to be $300 \mathrm{mmol} / \mathrm{m}^{2}$ body surface area per $\mathrm{h}$. Body surface area was calculated using a validated weightheight formula ${ }^{(31)}$. Data are displayed as the percentage of ${ }^{13} \mathrm{CO}_{2}$ dose recovered per $\mathrm{h}$ and the cumulative percentage of ${ }^{13} \mathrm{CO}_{2}$ recovered over time. The data were then fitted to a GE model developed by Ghoos et al. ${ }^{(32)}$. For all the data, $r^{2}$ coefficient between the modelled and raw data was calculated, and $r^{2}$ was $<0.95$ for all the test meals. From this model, several parameters were measured. Lag phase $\left(T_{\mathrm{lag}}\right)$ and half-time $\left(T_{\text {half }}\right)$ were calculated using the formulae derived by Ghoos et al. ${ }^{(32)} . T_{\text {lag }}$ is the time taken for the maximal rate of ${ }^{13} \mathrm{CO}_{2}$ excretion ${ }^{(33)}$ and is equivalent to the time of the inflection point ${ }^{(34)}$. $T_{\text {half }}$ is the time it takes for $50 \%$ of the ${ }^{13} \mathrm{C}$ dose to be excreted ${ }^{(33)}$. Latency phase $\left(T_{\text {lat }}\right)^{(34)}$ is the point of intersection of the tangent at the inflection point of the ${ }^{13} \mathrm{CO}_{2}$ excretion curve representing an initial delay in the excretion curve. Ascension time $\left(T_{\mathrm{asc}}\right)^{(34)}$ is the time course between $T_{\text {lat }}$ and $T_{\text {half }}$, representing a period of high ${ }^{13} \mathrm{CO}_{2}$ excretion rates.

\section{Measurement of viscosity}

Viscosity was measured in order to determine the change in rheological properties of the soups with differing molecular weights of BG. The viscosity of the soups was measured using a Bohlin Gemini 2 Rheometer (Malvern Instruments Limited) fitted with a cone and plate geometry $\left(2^{\circ}\right.$ cone angle and $55 \mathrm{~mm}$ diameter). All measurements were made at $37^{\circ} \mathrm{C}$ to mimic stomach temperature and at shear rates ranging from 0.02 to 20 per $s$.

\section{Statistical analysis}

Studies of the analysis of GR in humans have been based on ten subjects, as reviewed by the Food and Agricultural Organization/ $/ \mathrm{WHO}^{(24)}$ to take into account the inter-individual variations. Hence, a sample size of 12 was considered adequate for the present study, and fifteen subjects were recruited to avoid losses that may lead to errors in the sample size. Data collection was ended at the point at which fifteen subjects were recruited. Outcome measures consisted of GR, GE and DIT. Statistical analysis was performed using Statistical Package for the Social Sciences (version 20.0; SPSS), and the data and figures were processed in a Microsoft Excel spreadsheet (2006). The iAUC were determined for blood glucose, total DIT and fat oxidation using the trapezoidal rule for values above the baseline. The relative increment in the GR and energy expenditure at any time point compared with the baseline value was used to assess the differences at each time. Power calculation was done for the primary outcome measure of GE, $T_{\text {half }}{ }^{(35)}$. A sample size of 11 was required to detect a $40 \mathrm{~min}$ difference in $T_{\text {half }}$ with $\alpha$ set at 0.05 and a power of $90 \%$. The differences were assessed using a three-factor repeated-measures ANOVA. Where there was a main effect of meal type, pairwise comparisons were made using Sidak post hoc tests. Significance was set at $P<0.05$. Values are presented as means and standard deviations or as means with their standard errors.

\section{Results}

All fifteen volunteers completed all three trials fully. 


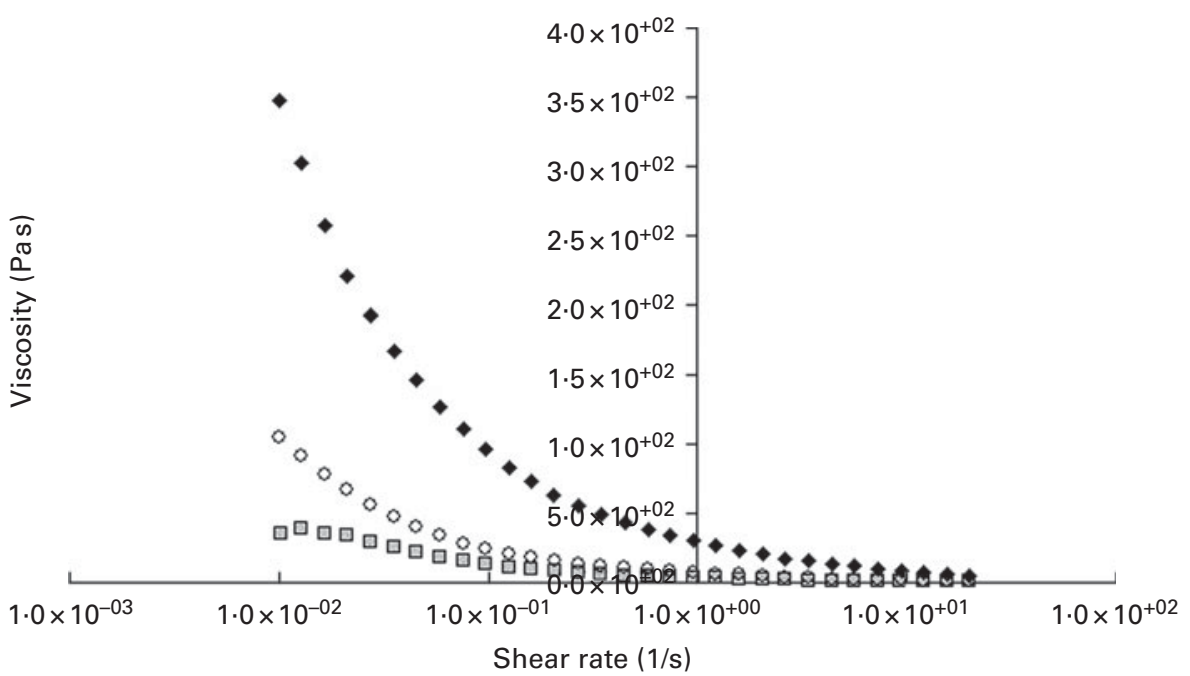

Fig. 1. Viscosity of the soups containing high-molecular-weight $\beta$-glucan (O), low-molecular-weight $\beta$-glucan ( $\diamond)$ or a control containing no $\beta$-glucan ( $\square$ ).

\section{Viscosity}

The viscosity of the HBG soup was considerably greater than that of either the CHO soup or the LBG soup (Fig. 1). Similar viscosities were demonstrated by the LBG and CHO soups. There was a significant difference between the viscosity of the HBG soup and that of the LBG soup $(P<0.05)$ and between the viscosity of the LBG soup and that of the $\mathrm{CHO}$ soup $(P<0.05)$ at a shear rate of 0.02 per s. A greater difference in viscosity was noted between the HBG soup and the CHO soup $(P<0 \cdot 01)$.

\section{Glycaemic response}

There was no significant difference in GR iAUC between the meals after $120 \mathrm{~min}$ (HBG meal: 84.0 (SD 41.2), LBG meal: $99 \cdot 0$ (SD 50.1), and CHO meal: $111 \cdot 1$ (SD 63.1) mmol $\times$ $\min / 1 ; P=0 \cdot 186)$; however, there was a significant difference in GR iAUC after $60 \mathrm{~min}$ (HBG meal: $40 \cdot 0$ (SD 17.6), LBG meal: $70 \cdot 4$ (SD 25.4), and $\mathrm{CHO}$ meal: $76 \cdot 4$ (SD 27.1) $\mathrm{mmol} \times$ $\min / 1 ; P<0 \cdot 001)$. Differences existed between the HBG and LBG meals and between the HBG and CHO meals, with the CHO and LBG meals having a greater GR than the HBG meal. Over the test duration, differences existed between the three meals at $15 \mathrm{~min}(P=0.043), 30 \mathrm{~min}(P<0.001), 45 \mathrm{~min}$ $(P=0.016)$ and $120 \mathrm{~min}(P=0.006$; Fig. 2$)$. For the LBG and $\mathrm{CHO}$ meals, the blood glucose levels rose rapidly and reached a peak at $30 \mathrm{~min}$ and declined rapidly from there. For the HBG meal also, the blood glucose levels also rose at $30 \mathrm{~min}$ and reached a much lower peak, but exhibited a slower decline, resulting in a greater GR than the LBG and $\mathrm{CHO}$ meals at $120 \mathrm{~min}$.

\section{Gastric emptying}

There were significant differences in all GE time points: $T_{\text {half: }}$ $P<0.001, T_{\mathrm{lag}}: P=0.001, T_{\mathrm{lat}}: P=0.02$, and $T_{\mathrm{asc}}: P<0.001$. For all time points, the HBG meal had the slowest GE time with the LBG and CHO meals having similar emptying times (Table 2).

There was a significant correlation between the GE $T_{\text {half }}$ and the GR $(P=0.024 ; r 0.344)$ and the GE $T_{\text {asc }}$ and the GR at $60 \mathrm{~min}(P=0.012 ; r 0.382)$ such that the shorter the GE time, the greater the GR.

\section{Energy expenditure}

The RMR were similar on each test day (HBG meal: 4.10 (SD 0.75) $\mathrm{kJ} / \mathrm{min}(0.98$ (sD 0.18) kcal/min), LBG meal: 4.06 (sD 0.84) kJ/min (0.97 (sD 0.20) $\mathrm{kcal} / \mathrm{min})$, and CHO meal: $4 \cdot 1$ (sD 0.16) $\mathrm{kJ} / \mathrm{min}(0 \cdot 97$ $(\mathrm{SD} 0.11) \mathrm{kcal} / \mathrm{min}) ; P>0 \cdot 05)$. There were significant differences in total DIT between the three test meals (HBG meal: $20 \cdot 9(\mathrm{SD} 18 \cdot 4) \mathrm{kJ}$ (5.9 (sD $4.4 \mathrm{kcal}$ ), LBG meal: $47 \cdot 3$ (sD $34 \cdot 7) \mathrm{kJ}$ (11.3 (sD 8.3) kcal),

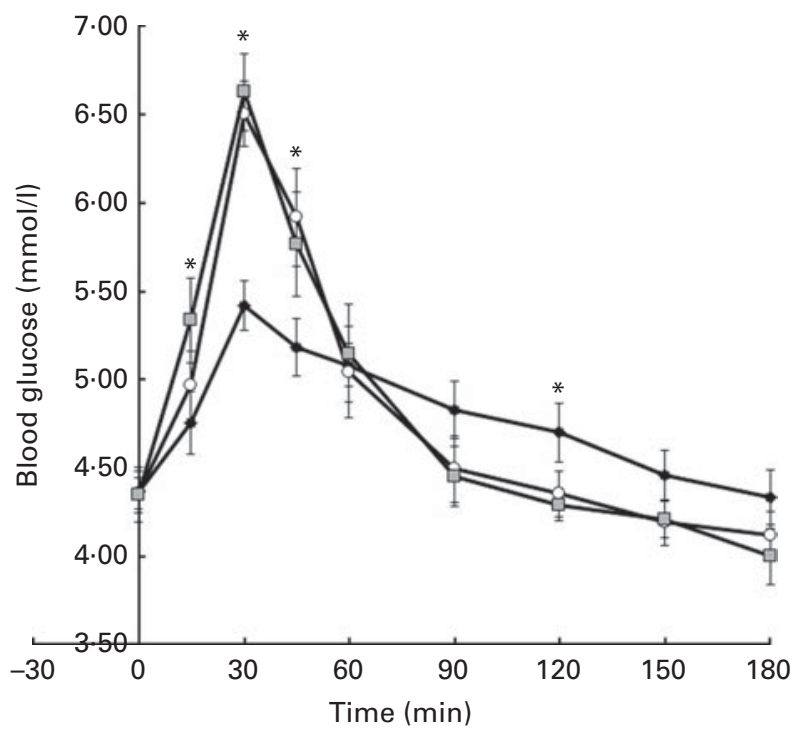

Fig. 2. Blood glucose response following the consumption of soups containing high-molecular-weight $\beta$-glucan ( $\bullet$ ), low-molecular-weight $\beta$-glucan (-o-) or a control containing no $\beta$-glucan $(\square)$. Values are means, with their standard errors represented by vertical bars $(n 15)$. ${ }^{*}$ Mean values were significantly different between the test meals $(P<0.05)$. 
Table 2. Gastric emptying times ( $\mathrm{min})$, half-time ( $\left.T_{\text {half }}\right)$, lag phase $\left(T_{\mathrm{lag}}\right)$, latency phase $\left(T_{\mathrm{lat}}\right)$ and ascension time $\left(T_{\mathrm{asc}}\right)$ of each of the soups containing either high-molecular-weight $\beta$-glucan (HBG), low-molecularweight $\beta$-glucan (LBG) or a control containing no $\beta$-glucan (CHO).

(Mean values and standard deviations, $n 15$ )

\begin{tabular}{|c|c|c|c|c|c|c|}
\hline \multirow{2}{*}{$\begin{array}{l}\text { Gastric emptying } \\
\text { time (min) }\end{array}$} & \multicolumn{2}{|c|}{$\mathrm{HBG}$} & \multicolumn{2}{|c|}{ LBG } & \multicolumn{2}{|c|}{$\mathrm{CHO}$} \\
\hline & Mean & SD & Mean & $\mathrm{SD}$ & Mean & SD \\
\hline$T_{\text {half }}{ }^{*}$ & $136 \cdot 8$ & 43.9 & $97 \cdot 1 \dagger$ & $13 \cdot 9$ & $99.2 \dagger$ & $11 \cdot 2$ \\
\hline$T_{\text {lag }}{ }^{*}$ & 83.5 & 32.3 & $60 \cdot 1 \dagger$ & $12 \cdot 6$ & $59.9 \dagger$ & 11.9 \\
\hline$T_{\text {lat }}{ }^{*}$ & $27 \cdot 1$ & $14 \cdot 2$ & 19.9 & $7 \cdot 2$ & $19.3+$ & $7 \cdot 1$ \\
\hline$T_{\text {asc }}{ }^{*}$ & $109 \cdot 8$ & 32.4 & $77.9 \dagger$ & $9 \cdot 0$ & $79.9 \dagger$ & 8.9 \\
\hline
\end{tabular}

${ }^{*}$ Mean values were significantly different between the test meals $(P<0.05)$.

$\dagger$ Mean values were significantly different from those of the HBG meal $(P<0.05)$.

and $\mathrm{CHO}$ meal: 43.5 (sD $26.4 \mathrm{~kJ}(10 \cdot 4$ (sD 6.3) kcal); $P=0.032)$. These differences existed between the HBG meal and the LBG meal $(P=0.037)$ and between the HBG meal and the $\mathrm{CHO}$ meal ( $P=0.015)$, with the HBG meal having the lowest DIT. These differences occurred at $60 \mathrm{~min}(P=0.021)$ and approached significance at 30 and $90 \mathrm{~min}(P=0.059$ and 0.058 , respectively; Fig. 3).

There was no significant difference in total fat oxidation between the three meals (HBG meal: 0.47 (SD 0.69), LBG meal: 0.43 (SD 0.61), and CHO meal: 0.60 (sD 0.61) g; $P>0.05$ ).

\section{Discussion}

The present study demonstrated that HBG has the ability to reduce GR and delay GE and that it has the lowest DIT in comparison with $\mathrm{LBG}$ and a control $(\mathrm{CHO})$.

It has been shown previously that BG has the ability to reduce GR, but this has not been shown in all studies ${ }^{(5-8)}$. Several reasons for this have been given in the previous literature. First, BG entraps glucose molecules and slows down their intestinal absorption, resulting in slower release of blood glucose ${ }^{(4)}$. Second, soluble viscous fibres contribute to the formation of an unstirred layer adjacent to the mucosa of the small-intestinal wall, and this layer acts as a physical barrier to the absorption of nutrients ${ }^{(36,37)}$. The present study provides another insight into why barley BG can reduce GR. Barley BG can form a viscous substance when placed in a solution as demonstrated by the rheological data presented. The higher the molecular weight, the greater the viscosity formed due to the entangling of the molecules ${ }^{(38)}$. The BG products used in the present study were LBG and HBG having molecular weights of 150 and $650 \mathrm{kDa}$, respectively, so there was a considerable difference between the two. The increased viscosity results in a slowed transit of food through the gastrointestinal tract. This was evident in the present study from the delayed GE for the HBG soup but not for the LBG soup, reflecting the viscosity data. The effect of GE was also mirrored in the GR data, which was similarly reduced in the HBG soup but not in the LBG soup or the control soup, and the two sets of data were correlated. The present data strongly indicate that the increased viscosity of the HBG soup delayed GE and delayed the delivery of nutrients into the duodenum, hence causing a lag in the uptake of glucose at the brush border, whereas the LBG soup did not. Previous research by our group has shown that BG with a low molecular weight does not influence $\mathrm{GR}^{(5)}$, whereas $\mathrm{HBG}$ does ${ }^{(39)}$. Juvonen et $a l .{ }^{(13)}$ reported an increase in glycaemic and insulinaemic responses and the acceleration of GE after a reduction in the viscosity of oat BG in a liquid meal. In another study, GR was reduced following the consumption of $4 \mathrm{~g}$ oat $\mathrm{BG}$ in a semi-solid meal, but there were no changes in the GE rate $^{(14)}$. However, in this study, the two test meals used did not contain the same amount of available carbohydrates as would be assumed in GR studies with the oat BG meal containing less available carbohydrates. It is likely that this may have caused the lower GR. The present study is the first to compare GE and GR after the ingestion of BG of different molecular weights and to demonstrate that the GE rate has a large influence on GR due to the increased viscosity.

An interesting finding of the present study was that the LBG and $\mathrm{CHO}$ meals had the ability to raise DIT significantly more than the HBG meal. Before commencing the present study,

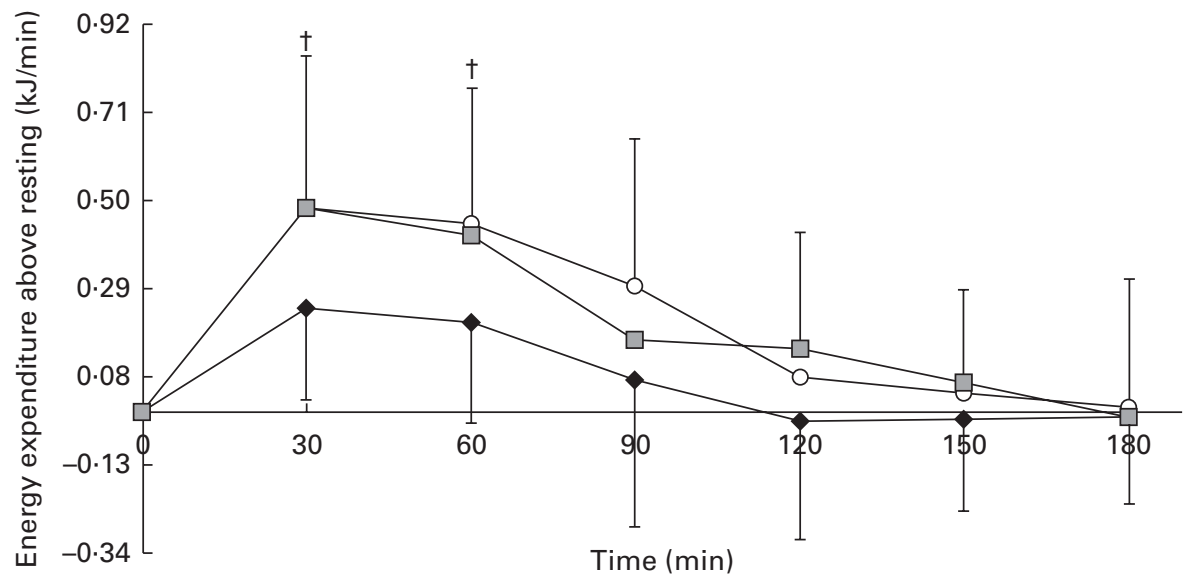

Fig. 3. Diet-induced thermogenesis following the consumption of soups containing high-molecular-weight $\beta$-glucan (HBG, - -), low-molecular-weight $\beta$-glucan $(-\circ)$ or a control containing no $\beta$-glucan (- $\square)$. Values are means, with standard deviations represented by vertical bars $(n 15)$. $\dagger$ Mean values were significantly different from those of the HBG meal $(P<0.05)$. Error bars for the LBG values were similar in magnitude to the other data and are not presented to improve clarity. 
it was hypothesised that adding barley BG to a semi-solid food would increase DIT and the effect would depend on its physicochemical properties such as molecular weight and viscosity. The authors proposed that the increased viscosity would cause an increase in DIT due to the extended time required to digest, absorb and assimilate the nutrients. This theory was supported by previous research that has shown that low-glycaemic index foods result in an increase in DIT ${ }^{(21)}$, which has been attributed to slower carbohydrate absorption and disposal, as a consequence of a slower GE rate, with consequent prolonged energy consumption for the absorption and storage of carbohydrates as glycogen and fat.

However, the opposite effect was observed in the present study with DIT being reduced following the consumption of the HBG test meal. A reduction in DIT after the consumption of a high-fibre meal than after the consumption of a low-fibre meal has been observed in other studies. Heijnen et al. ${ }^{(40)}$ found a reduction in DIT with the addition of resistant starch to a test meal. However, the study did not use equal amounts of digestible carbohydrates in the test meals and instead the resistant starch displaced digestible carbohydrates in the meal. Hence, the amount of available energy was reduced in the resistant starch test meal, which would cause a lower DIT due to lower amounts of carbohydrates to be transported and stored. Another study by Raben et al. ${ }^{(41)}$ found that with the addition of a pea fibre, DIT was reduced. The study hypothesised that the difference was not due to parasympathetic nervous stimulation but most likely due to sympathetic nervous stimulation due to either the rate of absorption, transport and storage of nutrients or the reduced palatability and cephalic responses of the fibre meal. The second hypothesis is further supported by palatability data obtained from rats ${ }^{(42)}$ and intubation studies that have shown that reducing the palatability or bypassing cephalic stimulation causes DIT to be reduced ${ }^{(43)}$. The present study did not assess the palatability of the two test meals with BG. However, responses from the participants indicated that the main difference in the soups was due to the increase in viscosity caused by the BG.

The reduction in DIT may also be attributed to the attenuation of GR and GE by HBG, which resulted in a retarded absorption of nutrients and a decrease in metabolisable energy. This is in agreement with the findings of Baer et $a l^{(44)}$, who proposed an inverse relationship between the intake of soluble fibres and metabolisable energy. Many studies have noticed the increased ability of high-molecularweight BG to lower serum lipid levels in comparison with low-molecular-weight BG. The ability of BG to bind with fat and decrease its absorption may also have caused the reduction in $\mathrm{DIT}^{(45-47)}$, although no changes were evident in fat oxidation during the $3 \mathrm{~h}$ test period. Similar to the effects on GR and GE, the addition of LBG in the soup did not result in a reduction in DIT, probably because it is less efficient in binding to fat and reducing its absorption or due to its inability to retard the absorption of glucose.

There are a few limitations to the present study. Although sufficiently powered for GE, the sample size might have been too small to detect changes in DIT and satiety (data not presented). The satiety testing was only based on subjective measures using the visual analogue scale and not on subsequent energy intake. Continuing the DIT measurement for a longer period of time is also recommended because the fibre might undergo fermentation and result in some changes in energy expenditure ${ }^{(48)}$.

In conclusion, the present study has highlighted the importance of retaining barley BG of a high molecular weight in foods in order to derive the beneficial effects on GR and GE. Although diets high in BG are recommended for weight loss, it may be noted that the effect is not mediated by an increase in postprandial DIT in the case of HBG. Hence, further studies are required to investigate the long-term effects of BG on energy expenditure.

\section{Acknowledgements}

The authors acknowledge Oxford Brookes University for providing financial support. P. S. T. and M. E. C. contributed to the study design, data collection, data analysis and writing of the manuscript. A. S. contributed to the data collection and writing of the manuscript. There are no conflicts of interest associated with this paper.

\section{References}

1. Ahmad A, Anjum FM, Zahoor T, et al. (2012) Beta glucan: a valuable functional ingredient in foods. Crit Rev Food Sci Nutr 52, 201-212.

2. El Khoury D, Cuda C, Luhovyy BL, et al. (2012) Beta glucan: health benefits in obesity and metabolic syndrome. $J$ Nutr Metab 2012, 851362.

3. Jenkins DJA, Marchie A, Augustin LSA, et al. (2004) Viscous dietary fibre and metabolic effects. Clin Nutr Suppl 1, 39-49.

4. Dikeman CL \& Fahey GC (2006) Viscosity as related to dietary fiber: a review. Crit Rev Food Sci Nutr 46, 649-663.

5. Thondre PS \& Henry CJ (2011) Effect of a low molecular weight, high-purity beta-glucan on in vitro digestion and glycemic response. Int J Food Sci Nutr 62, 678-684.

6. Keogh GF, Cooper GJ, Mulvey TB, et al. (2003) Randomized controlled crossover study of the effect of a highly betaglucan-enriched barley on cardiovascular disease risk factors in mildly hypercholesterolemic men. Am J Clin Nutr $\mathbf{7 8 ,}$ 711-718.

7. Smith KN, Queenan KM, Thomas W, et al. (2008) Physiological effects of concentrated barley beta-glucan in mildly hypercholesterolemic adults. J Am Coll Nutr 27, 434-440.

8. Chillo S, Ranawana DV, Pratt M, et al. (2011) Glycemic response and glycemic index of semolina spaghetti enriched with barley beta-glucan. Nutrition 27, 653-658.

9. Kristensen M \& Jensen MG (2011) Dietary fibres in the regulation of appetite and food intake. Importance of viscosity. Appetite 56, 65-70.

10. Brownlee IA (2011) The physiological roles of dietary fibre. Food Hydrocolloids 25, 238-250.

11. Juntunen KS, Niskanen LK, Liukkonen KH, et al. (2002) Postprandial glucose, insulin, and incretin responses to grain products in healthy subjects. Am J Clin Nutr $\mathbf{7 5}$, 254-262.

12. Hlebowicz J, Wickenberg J, Fahlstrom R, et al. (2007) Effect of commercial breakfast fibre cereals compared with corn 
flakes on postprandial blood glucose, gastric emptying and satiety in healthy subjects: a randomized blinded crossover trial. Nutr J 6, 22.

13. Juvonen KR, Purhonen AK, Salmenkallio-Marttila M, et al. (2009) Viscosity of oat bran-enriched beverages influences gastrointestinal hormonal responses in healthy humans. J Nutr 139, 461-466.

14. Hlebowicz J, Darwiche G, Bjorgell O, et al. (2008) Effect of muesli with $4 \mathrm{~g}$ oat beta-glucan on postprandial blood glucose, gastric emptying and satiety in healthy subjects: a randomized crossover trial. J Am Coll Nutr 27, 470-475.

15. Ludwig DS (2000) Dietary glycemic index and obesity. J Nutr 130, 280S-283S.

16. Raben A (2002) Should obese patients be counselled to follow a low-glycaemic index diet? No. Obes Rev 3, 245-256.

17. Raatz SK, Torkelson CJ, Redmon JB, et al. (2005) Reduced glycemic index and glycemic load diets do not increase the effects of energy restriction on weight loss and insulin sensitivity in obese men and women. J Nutr 135, 2387-2391.

18. Sloth B, Krog-Mikkelsen I, Flint A, et al. (2004) No difference in body weight decrease between a low-glycemic-index and a high-glycemic-index diet but reduced LDL cholesterol after 10-wk ad libitum intake of the low-glycemic-index diet. Am J Clin Nutr 80, 337-347.

19. Westerterp KR (2004) Diet induced thermogenesis. Nutr Metab (Lond) 1, 5.

20. Diaz EO, Galgani JE, Aguirre CA, et al. (2005) Effect of glycemic index on whole-body substrate oxidation in obese women. Int J Obes (Lond) 29, 108-114.

21. Scazzina F, Del Rio D, Benini L, et al. (2011) The effect of breakfasts varying in glycemic index and glycemic load on dietary induced thermogenesis and respiratory quotient. Nutr Metab Cardiovasc Dis 21, 121-125.

22. Pereira MA, Swain J, Goldfine AB, et al. (2004) Effects of a low-glycemic load diet on resting energy expenditure and heart disease risk factors during weight loss. JAMA 292, 2482-2490.

23. Khossousi A, Binns CW, Dhaliwal SS, et al. (2008) The acute effects of psyllium on postprandial lipaemia and thermogenesis in overweight and obese men. Br J Nutr 99, 1068-1075.

24. FAO/WHO (1998) Carbohydrates in human nutrition. Report of a Joint FAO/WHO Expert Consultation. FAO Food Nutr Pap 66, 1-140.

25. Reed GW \& Hill JO (1996) Measuring the thermic effect of food. Am J Clin Nutr 63, 164-169.

26. Lusk G (1928) The Elements of the Science of Nutrition. London: WB Saunders Company.

27. Brouns F, Bjorck I, Frayn KN, et al. (2005) Glycaemic index methodology. Nutr Res Rev 18, 145-171.

28. Stork AD, Kemperman H, Erkelens DW, et al. (2005) Comparison of the accuracy of the HemoCue glucose analyzer with the Yellow Springs Instrument glucose oxidase analyzer, particularly in hypoglycemia. Eur J Endocrinol 153, 275-281.

29. Wolever TMS (2006) The Glycaemic Index: A Physiological Classification of Dietary Carbohydrate. Wallingford: CABI.

30. Braden B, Adams S, Duan LP, et al. (1995) The $\left[{ }^{13} \mathrm{C}\right]$ acetate breath test accurately reflects gastric emptying of liquids in both liquid and semisolid test meals. Gastroenterology $\mathbf{1 0 8}$, 1048-1055.

31. Haycock GB, Schwartz GJ \& Wisotsky DH (1978) Geometric method for measuring body surface area: a height-weight formula validated in infants, children, and adults. $J$ Pediatr 93, 62-66.
32. Ghoos YF, Maes BD, Geypens BJ, et al. (1993) Measurement of gastric emptying rate of solids by means of a carbonlabeled octanoic acid breath test. Gastroenterology $\mathbf{1 0 4}$, $1640-1647$.

33. Jackson SJ, Leahy FE, McGowan AA, et al. (2004) Delayed gastric emptying in the obese: an assessment using the non-invasive (13)C-octanoic acid breath test. Diabetes Obes Metab 6, 264-270.

34. Schommartz B, Ziegler D \& Schadewaldt P (1998) Significance of diagnostic parameters in $\left[{ }^{13} \mathrm{C}\right]$ octanoic acid gastric emptying breath tests. Isotopes Environ Health Stud 34, $135-143$

35. Markey O, McClean CM, Medlow P, et al. (2011) Effect of cinnamon on gastric emptying, arterial stiffness, postprandial lipemia, glycemia and appetite responses to high fat breakfast. Cardiovasc Diabetol 10, 78 .

36. Wursch P \& Pi-Sunyer FX (1997) The role of viscous soluble fiber in the metabolic control of diabetes. A review with special emphasis on cereals rich in beta-glucan. Diabetes Care 20, 1774-1780.

37. Schneeman BO (2001) Dietary fibre and gastrointestinal function. In Advanced Dietary Fibre Technology, pp. 168-176 [BV McCleary and L Prosky, editors]. Oxford: Blackwell Science.

38. Anttila H, Sontag-Strohm T \& Salovaara H (2004) Viscosity of beta-glucan in oat products. Agricult Food Sci 13, 80-87.

39. Thondre PS \& Henry CJ (2009) High-molecular-weight barley beta-glucan in chapatis (unleavened Indian flatbread) lowers glycemic index. Nutr Res 29, 480-486.

40. Heijnen ML, Deurenberg P, van Amelsvoort JM, et al. (1995) Replacement of digestible by resistant starch lowers dietinduced thermogenesis in healthy men. Br J Nutr $\mathbf{7 3}$, 423-432.

41. Raben A, Christensen NJ, Madsen J, et al. (1994) Decreased postprandial thermogenesis and fat oxidation but increased fullness after a high-fiber meal compared with a low-fiber meal. Am J Clin Nutr 59, 1386-1394.

42. LeBlanc J \& Labrie A (1997) A possible role for palatability of the food in diet-induced thermogenesis. Int $J$ Obes Relat Metab Disord 21, 1100-1103.

43. LeBlanc J, Cabanac M \& Samson P (1984) Reduced postprandial heat production with gavage as compared with meal feeding in human subjects. Am J Physiol $\mathbf{2 4 6}$ E95-E101.

44. Baer DJ, Rumpler WV, Miles CW, et al. (1997) Dietary fiber decreases the metabolizable energy content and nutrient digestibility of mixed diets fed to humans. J Nutr 127, $579-586$.

45. Braaten JT, Wood PJ, Scott FW, et al. (1994) Oat beta-glucan reduces blood cholesterol concentration in hypercholesterolemic subjects. Eur J Clin Nutr 48, 465-474.

46. Cugnet-Anceau C, Nazare JA, Biorklund M, et al. (2010) A controlled study of consumption of beta-glucan-enriched soups for 2 months by type 2 diabetic free-living subjects Br J Nutr 103, 422-428.

47. Torronen R, Kansanen L, Uusitupa M, et al. (1992) Effects of an oat bran concentrate on serum lipids in free-living men with mild to moderate hypercholesterolaemia. Eur J Clin Nutr 46, 621-627.

48. Gao Z, Yin J, Zhang J, et al. (2009) Butyrate improves insulin sensitivity and increases energy expenditure in mice. Diabetes 58, 1509-1517. 